\title{
Resistencias LGBT en universidades de Chiapas, México: más allá de la víctima pasiva
}

\section{LGBT resistance in universities in Chiapas, Mexico: Beyond the passive victim}

\author{
Arturo Gerardo Ruiz Utrilla* \\ Angélica Aremy Evangelista García** \\ doi.org/10.29043/liminar.v20i2.908
}

Resumen: El presente artículo tiene el objetivo de exponer y analizar las formas de resistencia de estudiantes LGBT en tres universidades públicas de Chiapas, México, frente a manifestaciones diversas de violencia y discriminación. La investigación se desarrolló con base en una metodología cualitativa, y la información se analizó por medio de la estrategia de la teoría fundamentada. Entre los resultados encontramos que las y los estudiantes LGBT no son víctimas pasivas de la discriminación, sino que se resisten de formas variadas, lo que hace de la universidad un espacio de disputa frente al dictado heteropatriarcal.

Palabras clave: estudiantes LGBT, discriminación, educación superior.

Abstract: This paper aims to expose and analyze how LGBT students in three public universities in Chiapas, Mexico, are carrying out forms of resistance in response to manifestations of violence and discrimination. The research was based on a qualitative methodology and analyzed through a groundedtheory strategy. We found that LGBT students are not passive victims of discrimination, but rather resist in various ways, making the university a space in dispute over heteropatriarchal norms.

Key words: LGBT students, discrimination, higher education.

Recibido: 25 de enero de 2021

Aprobación: 7 de junio de 2021

Publicación: 28 de enero de 2022
* El Colegio de la Frontera Sur, San Cristóbal de Las Casas, Chiapas, México agruiz@ecosur.edu.mx (iD) 0000-0001-7568-7175

** El Colegio de la Frontera Sur, San Cristóbal de Las Casas, Chiapas, México aevangel@ecosur.mx D) 0000-0002-4460-854X 


\section{Planteamiento}

$\mathrm{E}$ 1 presente artículo tiene el objetivo de analizar y exponer las prácticas de resistencia que, al lado de la vulnerabilidad y la discriminación, constituyen una dimensión de la experiencia universitaria de las y los estudiantes LGBT. Este trabajo forma parte de una investigación más amplia que tuvo el objetivo de analizar la experiencia del estudiantado LGBT en la universidad. Entre los hallazgos se ha revelado que la universidad es un lugar de riesgos donde se observan patrones de poder/subyugación que sitúan al estudiantado LGBT en condiciones de desventaja social y académica. La categoría que ha dado cuenta de estos actos es la LGBT-Discriminación (LGBT-D). Sin embargo, ¿la experiencia de estudiantes LGBT solo se produce por medio de estos actos de vulneración? ¿Será que siempre son víctimas de las políticas culturales e institucionales en el interior de la universidad, políticas que se resumen en nuestro concepto de LGBT-D? ¿No habrá en su experiencia resistencias, agencias y vindicaciones?, ¿o solo son receptáculos de la historia y de las fuerzas prácticas de las opresiones? Nuestra investigación da cuenta de que existe en la práctica otra dimensión de su experiencia como estudiantes y seres humanos: la resistencia.

\section{Posicionamiento conceptual}

Las universidades, como las instituciones de todo nivel educativo, enfrentan un reto complicado: atender el derecho educativo basado en el modelo de calidad en medio de un contexto de diversidades. Nos damos cuenta del tamaño del encargo cuando reconocemos que la escolaridad es un fenómeno compuesto interseccionalmente por patrones de poder/subyugación tales como la clase, la raza, el origen, la orientación sexual y la identidad de género, lo que integra un sistema complejo de producción de identidades (Platero, 2012) que transciende los elementos exclusivamente académicos. Ante este panorama, el estudiantado LGBT se ve en desventaja, independientemente del nivel educativo del que se trate. ${ }^{1}$

Ahora bien, la investigación que hemos desarrollado hasta la fecha, junto con las discusiones producidas por medio del diálogo entre el material empírico y los recursos conceptuales, hacen especial énfasis en la dimensión de la discriminación, y de ello se da cuenta por medio de la categoría de la LGBT-D $^{2}$ (Ruiz, Evangelista y Xolocotzi, 2018). Esta experiencia de las y los estudiantes LGBT está esencialmente marcada por la negación o, como Bourdieu menciona, por el "rechazo de la existencia legítima y pública, es decir conocida y reconocida", por "el tabú de la feminización sacrílega de lo masculino" (Bourdieu, 1998, p. 144).

Esto es un efecto del panoptismo (Foucault, 1980, 2002), donde el género se muestra como un dispositivo de poder (Amigot y Pujal i Llombart, 2009) y la sexualidad en general se vuelve un mecanismo de regulación y normalización (Foucault, 1998), dispuesto a la vigilancia de la sociedad y no únicamente centralizado en las instituciones sociales. Entonces: "El cuerpo tiene una dimensión

\footnotetext{
${ }^{1}$ Ver: Baruch et al. (2017), CIDH (2015), Diagnóstico sobre atención... (2017), Otero (2017), Otero y Martínez (2016), Movilh (2010), Piña y Aguayo (2015), Portugal (2011); Proceso (2017) y UNESCO (2013, 2015a, 2015b).

${ }^{2}$ El concepto LGTB-D se desarrolló de manera amplia en un trabajo previo. Se refiere a una forma de discriminación que surge a partir de la construcción social de rechazo contra las personas LGBT, que, además de lacerar en algún modo a la víctima, funciona en la reproducción de los valores heteropatriarcales.
} 
invariablemente pública. Constituido en la esfera pública como un fenómeno social, mi cuerpo es y no es mío" (Butler, 2006, p. 52).

Como Butler, encontramos algunos cuestionamientos a las nociones fundantes del concepto de género: la posición binaria de sexo/género, entendida como biología/cultura, de manera oculta considera el sexo, estructura innata de los cuerpos, como la posibilidad de existencia del género y como su restricción ontológica. En tanto el sexo es dual —macho y hembra—, ello implicaría que el género se manifestara en la existencia de hombres y mujeres, masculinidad y feminidad. Desde esta perspectiva no se puede explicar la existencia de la diversidad sexual. Butler cuestiona este esquema al no encontrar fundamentos en estricto sentido: "aunque los sexos parezcan claramente binarios en su morfología y constitución (lo que tendrá que ponerse en duda) no hay ningún motivo para creer que los géneros sigan siendo dos" (Butler, 2007, p. 54). Además, el género se encuentra igualmente atrapado en la misma dicotomía desde la perspectiva de su construcción social, ya que esta se funda en la matriz heteronormativa, lo que debería devenir en la generación de hombres masculinos y mujeres femeninas, sin dar cuenta de la existencia de personas LGBT: "La hipótesis de un sistema binario de géneros sostiene de manera implícita la idea de una relación mimética entre género y sexo, en la cual el género refleja al sexo” (Butler, 2007, p. 54).

Pensamos el género, entonces, desde una perspectiva posidentitaria, como puro tránsito, sin fin, sin llegada, únicamente como un proceso que no tiene estabilidad y es puro pas(e)ar, un recrear continuo pese a la normas y dictados de reiteración que restringen las posibilidades (De Oliveira, 2019).

Sin embargo, aun siendo así, la ficción de un género estable funciona como ideal regulatorio y, en el mismo sentido, la sexualidad ejerce como un mecanismo de regulación, imposición, poder y subyugación, constituyendo identidades llenas de prerrogativas visibles, aceptadas y puestas como patrones, pero también constituye, dialécticamente, sus antípodas: sexualidades desposeídas, abyectas y dispuestas a la normalización, como el caso de las sexualidades diversas, dando contenido a una biopolítica (Foucault, 2007).

Desde esta perspectiva, la experiencia LGBT en el interior de las universidades, en el transcurso de la producción de datos e interpretaciones, ha dado cuenta de su currículum social como mecanismo regulador de las sexualidades y corporalidades vía interacciones intersubjetivas y espontáneas, pero también por medio del currículum oculto. Sin embargo, entre las posibilidades que se pronostican desde la pedagogía crítica y desde la teoría de la resistencia, existe otra dimensión de la experiencia de las y los estudiantes LGBT: la resistencia.

La pedagogía crítica ha dedicado grandes esfuerzos para comprender cómo el sistema educativo participa en la reproducción social más allá de las posturas clásicas y estructurales. Uno de esos elementos que mantienen vigente la pedagogía crítica es el concepto de resistencia porque transciende la visión reduccionista de la escuela en general y de la universidad en particular como transmisoras pasivas de las ideologías de los grupos dominantes. Se trata de una entidad activa que reproduce, actualiza y crea procesos y mecanismos de subyugación, pero también resistencias.

Sin embargo, estos actos y discursos de dictado y resistencia no se deben entender como aislados, sino como elementos de una dinámica ritualista (McLaren, 1998). Estos actos rituales, sea de reproducción o de contestación, son parte del entramado polimórfico y complejo que compone la escolaridad.

En este conjunto dialéctico, el concepto de resistencia nos lleva a considerar la universidad a través de esquemas de ideologías y contraideologías, de represión y contestación, de dictados y contradiscursos (Giroux, 1992), es decir, como un espacio en tensión y conflicto. 
Así, aunque la mayoría de las investigaciones o diagnósticos que existen sobre diversidad sexual en contextos escolares centran su atención exclusivamente en las formas de vulneración a las que están expuestos los y las estudiantes LGBT, los teóricos de la resistencia aportan elementos conceptuales y empíricos para suponer que la construcción del género, junto con otras matrices de opresión, no se reproduce totalmente en los ámbitos educativos: "los mecanismos de la reproducción social y cultural nunca son completos y siempre encuentran elementos de oposición parcialmente manifiestos" (Giroux, 1985, p. 40).

Entendemos "resistir" como la afirmación frente a un proceso de negación de la identidad. Como puede observarse, este sentido positivo de la resistencia se desdobla como negación de la negación: desobediencia y subversión a la desposesión, subyugación, injusticia y violencia, producto de una lógica diferencial. Coincidimos con Scott en que la resistencia necesita de la negación normativa de la ideología dominante, aunque esta contraideología se construya, legitime y difunda en los propios espacios de insubordinación como discursos ocultos (Scott, 2000), como una de sus posibilidades ante la presencia del poder.

\section{Metodología}

El artículo que aquí se presenta es parte de una investigación más amplia que tiene el objetivo de realizar una reconstrucción fenomenológica-hermenéutica (Heidegger, 2009) acerca de la universidad desde la perspectiva de sus estudiantes LGBT. La investigación busca responder a las siguientes preguntas: ¿cuál es el significado de la universidad desde la experiencia de las y los estudiantes LGBT? y ¿ cuál es el sentido social y educativo que se avizora desde la experiencia que han construido de ella sus estudiantes con opciones sexuales no hegemónicas? Por el planteamiento teórico, la experiencia de las y los estudiantes LGBT es rastreada por medio de dos dimensiones: la LGBT-D y la resistencia, siendo la última el objeto de presentación de este trabajo.

La investigación se llevó a cabo en tres universidades públicas ${ }^{3}$ ubicadas en los centros urbanos de Tapachula y San Cristóbal de Las Casas, ${ }^{4}$ Chiapas, México, en el intervalo de 2017 a 2020. Se utilizó una metodología cualitativa y técnicas de obtención de datos tales como entrevistas a profundidad, grupos focales y cartas asociativas con 16 estudiantes LGBT y 30 participantes claves - estudiantes heterosexuales, personal docente, directivo y coordinador-. En este artículo se exponen los hallazgos referidos a la categoría de resistencia generados a partir de preguntas detonadoras relacionadas con cómo se actuó frente a la agresión, ya sea como víctima o como testigo de esta. En tal sentido, se recuperan narrativas de nueve estudiantes (gais, no binario y bisexual) y cuatro actores clave en las que es posible reconocer actos de resistencia.

Desde esta categoría se fueron identificando, a partir del dato, subcategorías relacionadas con elementos que la integraban, sus dimensiones, sus manifestaciones en una forma de tipología generada por

\footnotetext{
${ }^{3}$ En San Cristóbal de Las Casas se trabajó con estudiantes de las carreras de Comunicación Intercultural, Lengua y Cultura, y de Medicina, de la Universidad Intercultural de Chiapas (UNICH), mientras que en Tapachula se trabajó con estudiantes de distintas carreras de Ingeniería impartidas en el Instituto Tecnológico y de la Licenciatura en Pedagogía de la Universidad Autónoma de Chiapas (UNACH).

${ }^{4}$ En 2010 San Cristóbal de Las Casas contaba con 215874 habitantes (Secretaría de Economía, 2021a), mientras que Tapachula contaba con 353756 habitantes (Secretaría de Economía, 2021b).
} 
medio del microanálisis, la codificación abierta e in vivo y el análisis axial, tal como lo propone la teoría fundamentada (Strauss y Corbin, 2002) y utilizando para ello el programa NVivo 11.

La participación de estudiantes LGBT se dio a partir de criterios como: ser estudiante de las universidades seleccionadas, asumirse con una opción sexual no hegemónica y aceptar participar en la investigación por medio de consentimiento informado. La confidencialidad se salvaguardó utilizando seudónimos y omitiendo información que podría vulnerar la integridad de quienes participaron en la investigación. Se empleó la estrategia de bola de nieve para el muestreo en las etapas más tempranas de la investigación; esto se realizó solicitando permisos a las autoridades antes de sostener cualquier interacción con el estudiantado, a partir de diálogos informales en espacios universitarios sobre la presencia de personas LGTB, así como con quienes aceptaron participar en entrevistas después de acercarse al final de charlas y conferencias académicas que impartió el primer autor de este artículo. En fases más avanzadas del proyecto de investigación optamos por un muestreo teórico con la intención específica de abarcar diversas identidades LGBT; así, por medio de participantes clave que actuaron como mediadores, se contactó a estudiantes LGBT que autorizaron otorgar su número de teléfono para entablar comunicación y acordar la fecha para realizar la entrevista.

Finalmente, se incluyen a pie de página las presentaciones de las y los participantes de este estudio desde una perspectiva autobiográfica. Se decidió este enfoque por la naturaleza fenomenológica de este estudio, frente a aquel otro más ortodoxo de llenado de matrices con características sociodemográficas preestablecidas.

\section{Resultados}

A continuación presentamos el análisis de las experiencias del estudiantado LGBT a partir de la categoría de la resistencia entendida como la afirmación frente a un proceso de negación de la identidad. Incluimos las siguientes subcategorías que emergieron del análisis del dato como modalidades prácticas del mismo acto de resistencia: confrontación, provocación y resistencia estratégica.

\section{a) Confrontación}

La confrontación se define como la oposición práctica a un intento de discriminación en cualquiera de sus facetas. Habitualmente es una respuesta reactiva e inmediata ante la discriminación. En tanto reactiva hacia la discriminación, suele ser relacional con esta; se da en los mismos márgenes de la violencia. Es una respuesta que trata de anular la negación concomitante de la discriminación: "Uno me dijo que era un puto, que por ser gay me creía. Y yo: ‘'ya estuve contigo? ¿En qué borrachera me la mamaste?'. Lejos de sentirme ofendido, los chiveados son los otros. Esa es mi forma, y creo que no es mala" (GF LGBT, gay, P5). ${ }^{5}$

Lourdes presenció esta forma de confrontar la vejación:

\footnotetext{
${ }^{5}$ Las siglas "GF LGBT, P5", se refieren a lo siguiente: GF, grupo focal como técnica de obtención de datos; LGBT corresponde al nombre del grupo focal, que en este caso hace referencia a participantes con identidades sexogenéricas no hegemónicas; y "P5", se refiere al participante (P) y al orden en el que hizo su primera intervención (5).
} 
En esa ocasión él [su amigo] se fue de fiesta con el grupo de Civil. Después que regresaron se escuchaba que se había chingado a dos o tres niños de ahí, pero cuando estaban pedos. Entonces, cuando lo querían molestar, él les decía: “Cállate, si ya te paré las patas”; y cuando le preguntaban si era cierto, decía: "Sí, sí me lo chingué, pregúntale cómo quedó”. Pero también era como una respuesta porque lo humillaban. Entonces, cuando él les decía: "Si ya te paré las patas y más pedías", los hombres pues pensaban que: “Cómo van a pensar que me den", o algo así. Y era algo como raro, "si tú vas a hablar de mí, por lo menos voy a decir que yo te chingué a ti, no que tú me chingaste a mí” (Lourdes, bisexual, Ingeniería Industrial). ${ }^{6}$

Así, las y los estudiantes gais utilizan los mismos elementos simbólicos del heterosexismo, como la producción de una disminución por medio de hacer pasar al otro como la figura receptiva y pasiva sexualmente, lo cual, han aprendido, inhibe el desarrollo de la vejación de forma tajante, por lo menos en la inmediatez del hecho.

Las y los estudiantes LGBT, en su misma cotidianidad, han aprendido a identificar los elementos que intervienen en las prácticas de discriminación que padecen, al punto que también han aprendido a contrarrestarlas. Alex, en su narrativa, presenta un matiz en este tipo de confrontación, como lo expresa:

Por ejemplo, ahora me molestan mucho con otro muchachito de ahí [...] Le decían, "tú le gustas a él" con tal de hacerme sentir mal a mí. Como que les volteé la tortilla y les seguí la corriente. Entonces, empezaba yo también a molestarlo. En vez de molestarme a mí, ahora lo molestan a él. Se pone como rojito y a veces hasta lo hacen enojar. Cuando comenzaba a molestarlo yo, se ponía serio y seguía en lo que estaba. También, les decía a mis compañeros: "Ya dejen de andar chingando". Muchas veces se levantaba y se iba, con tal de que no lo molestaran más (Alex, gay, Ingeniería en Gestión Empresarial).?

De acuerdo con el testimonio anterior, Alex no confronta a sus pares en los términos de las citas anteriores. La forma de confrontar y resistir este tipo de violencia es produciendo la exacerbación de su supuesta feminidad, y "sigue la corriente" hasta producir incomodidad en sus atacantes. Incrementa el elemento indeseable, el mismo que le están atribuyendo, hasta el punto de que su "anormalidad" resulta intratable, irritable.

La confrontación no solo se genera contra sus pares, sino también se oponen a la misma autoridad inmediata, sus docentes.

\footnotetext{
${ }^{6}$ Mujer, lesbiana, 24 años, octavo semestre. Se describe del siguiente modo: "Emocionalmente soy una persona estable, centrada, pero también muy fácil de manipular cuando me encuentran el modo. Tiene que pasar mucho tiempo para que pueda abrirme con una persona, pero, precisamente por eso, llega un punto en que sé que puedo ser yo totalmente. Soy una persona sensible, pero no me gusta expresarlo... Soy muy miedosa, no al daño físico, sino emocional... En el aspecto físico, estoy muy conforme con lo que soy. Me considero una persona guapa, atractiva... Cuando empecé la universidad, antes de primer semestre, todas mis relaciones habían sido heterosexuales. No tenía la noción de que iba a tener esa orientación".

${ }^{7}$ Hombre, gay, estudiante de tercer semestre. Considera que es "algo complicado. Soy una persona feliz, pero a la vez con una que otra dificultad... de la escuela, de mi casa, y no siempre tiene que ver con mi orientación sexual. Aunque siempre hay problemas me gusta verme emocionalmente bien, muy pocas veces me han visto triste mis amigas. No me gusta que me vean débil, es decir, no me gusta que me vean triste o llorando. Soy muy tímido. Soy un chico gay. Desde la primaria había un compañero que a mí me gustaba, pero me decía que eso no estaba bien. En la secundaria no me fijé en nadie, ni por hombre, ni por mujer. Tuve una novia, al final sirvió para descubrir quién era”.
} 
Incluso, como mi tesis era acerca de eso [diversidad sexual] me la cuestionaron bastante: ““”Por qué género?". Incluso tuvimos un debate con algún maestro de que género era hombre y mujer, nada más: "Estás mal" [le decía el maestro]. Yo le decía que es solo desde su perspectiva y lo que ha leído, le di una hoja de bibliografía y le dije que hay gente que habla de género desde la diversidad sexual. Sí me lo cuestionaban: “Por qué género? ¿Por qué la comunidad LGBT? ¿Por qué gais y lesbianas?” (Alberto, gay, Pedagogía). ${ }^{8}$

Una forma en la que se presenta la LGBT-D es la invisibilización, no otorgar reconocimiento a las personas $y$, en este caso, a lo que tenga que ver con la diversidad sexual. Incluso, en este caso, no se reconoce la diversidad sexual como objeto de estudio. Pese a la autoridad del docente, a la situación de Alberto como estudiante LGBT y al señalamiento oculto que se le estaba realizando en ese momento - un señalamiento público, frente a toda la clase-, Alberto, lejos de renunciar o de "zafarse" de la situación siendo condescendiente con el maestro, lo confronta, igual, públicamente. Le dice "no" a la autoridad de conocimiento, le replica y, podemos pensar, hasta lo provoca entregándole "una hoja de bibliografía", un gesto que podría resultar para algunos excesivo.

\section{b) Provocación}

Entendemos por provocación un acto en el que de manera intencionada se pretende generar reacciones frente a los elementos que giran alrededor de la diversidad sexual. Es un acto que consideramos que parte de una actitud de rebeldía, y al mismo tiempo de reivindicación. La provocación se instiga, incita, polemiza, suscita y construye sobre las bases de lo abyecto. También es una especie de desafío a lo que se concibe como normal y a sus agentes; aguijonea la incomodidad, el odio, la enemistad, los excita de manera consciente para propiciar la reacción y desde ahí tener la oportunidad de reivindicar.

En el siguiente caso, comentado por varios participantes, una estudiante se sintió aludida ante el comentario en clase de una docente que calificó de pecado y de anormal las opciones sexuales diversas. La reacción de la docente fue generada por un acto intencional de la estudiante en cuestión: “[...] me comentó que dentro de la exposición dejó la bandera LGBT en la diapositiva para ver qué decía la maestra, porque también los muchachos te miden y la profesora salió con ese comentario desafortunado" (Daniela, profesora de asignatura). ${ }^{9}$

Así, la estudiante, como parte de la población LGBT, no es una receptora pasiva de las vejaciones, sino que provoca la reacción a partir de una postura de sus pares y su docente como una oportunidad de reconocer el ambiente en el que se encuentra y también para debatir posibles discursos de intolerancia.

\footnotetext{
${ }^{8}$ Hombre, gay, 23 años, octavo semestre. Se describe del siguiente modo: "Una persona responsable, buena gente, altruista, principalmente feliz o alegre. Me di cuenta de mi orientación sexual desde el preescolar... pues la verdad, nunca fui como una persona homosexual o sujeto gay, no fui de juntarme solo con niñas. En el kínder me juntaba con los niños, me gustaba jugar futbol... Había un niño que me llamaba la atención en el preescolar. Supongo que desde ese momento lo sabía, aunque no sabía lo que me pasaba, sentir atracción hacia una persona del mismo sexo. En la primaria fue un poco más fuerte en ese sentido, me gustaba un niño, no me gustaba una niña. Entonces siguió, lo reafirmé [...] En la primaria no me tocó sufrir tanto, [...] no me bulleaban tanto, no me acosaban tanto. Igual porque no seguía los estereotipos de una persona homosexual. Me la pasé relajado. Pero, no faltaba alguno que otro insulto. Hacia algún gesto o algo y me decían ‘Güey, por qué haces eso”.
}

${ }^{9}$ Candidata a doctora por la Universidad Autónoma Metropolitana, tiene 35 años. Se define como mujer heterosexual. 
La provocación es una oportunidad para abrir el escenario respecto a la LGBT-D y desmontar las ideas que la promueven:

- Entonces, ¿prefiere que duerman en la calle?

- No, pero no se me hace adecuado [la adopción homoparental].

- ¿O que los viole un sacerdote? ¿O que no les den amor?

- No, pero mi pensamiento es ese, respétalo.

- No, pues que feo pensamiento porque los está discriminando (Lizzet, heterosexual, Pedagogía). ${ }^{10}$

Así, la provocación no actúa sola, sino que es una oportunidad para dar continuidad a la resistencia y la reivindicación por medio, ahora, de la confrontación. Otra de las maneras de operar la provocación, como forma de resistencia, es acentuar el elemento LGBT que genera un acto de discriminación, como una forma de exacerbar el imaginario al punto que resulte incómodo seguir con tal acto:

Cuando me ofenden, mi forma de reaccionar es seguirles la corriente. En vez de que me sienta ofendido hago que se chiveen, hasta que se pongan rojitos a veces, pero que yo le sigo, le sigo y le sigo. Pero no es lo correcto, porque tienes que defenderte educadamente y decirle: "Oye, respétame, es mi forma de ser y de pensar, no tienes por qué hablar mal de mí si yo no te estoy ofendiendo". No hago esto porque creo que da mejor resultado seguir molestando, es mejor hacerlo sentir mal (Alex, gay, Ingeniería en Gestión Empresarial).

Enrique expone otra forma de provocación con mayor alcance:

Esta pieza que tengo se llama septum. ${ }^{11}$ En la Edad Media se supone que significaba esclavitud. Se los ponían a las personas para que los demás supieran que eran esclavos. Después se volvió una moda, no tiene mucho, hace como diez años atrás. En Tapachula no he visto muchas personas con esta pieza. En San Cristóbal me la puse, ahí hay muchas personas que la usan. Más que su significado, me gustó mucho [...] A mí me criticaron mucho cuando me puse esa pieza, pero esto tiene un significado de que yo hago lo que quiera con mi vida y con mi cuerpo (Enrique, gay, Pedagogía). ${ }^{12}$

Tomando en cuenta el significado que le atribuye Enrique al septum, ¿cómo entender esta autoestigmatización? ¿Cómo preferir por voluntad el estigma a un rostro sin mácula? Aunque Enrique yerra en el significado original del septum, asociado espiritualmente a la fecundidad primero, luego usado

\footnotetext{
${ }^{10}$ Solicitó no revelar datos de su identidad.

${ }^{11}$ El septum es el cartílago que divide las fosas nasales. El piercing conocido con el mismo nombre es una argolla que se pone en esta ubicación.

${ }^{12}$ Hombre, gay, 21 años, quinto semestre. Se concibe del siguiente modo: "Soy una persona poco tolerante, a las personas que no me caen bien, no puedo ni verlas. Puedes estar pasando en la calle, pero si hay algo que no me gusta, te catalogo como algo que me cae mal. A veces suelo ser muy molestón. Soy así a partir de la universidad. De alguna manera tiene que ver con mi rebeldía. Soy muy sincero. Aunque en la secundaria era muy tímido. Cambié mucho en la prepa, creo que fue por el cambio de amistades. También soy muy bromista, haciendo relajo todo el tiempo. Soy muy confianzudo y llevado".
} 
para reconocer a las mujeres casadas, es importante para nuestros objetivos actuales hacer énfasis en que Enrique le da el significado de un estigma, de una marca visible para reconocer a los esclavos. Así, por su rareza en la región, el uso del septum refuerza la vigilancia a la que se encuentra expuesto, acentúa socialmente su extravagancia, originalmente solo asociada con su homosexualidad. Existe para él un sentido de rebeldía y contestación a los patrones simbólicos de normalidad que su sociedad inmediata impone y acepta: "Yo hago lo que quiera con mi vida y con mi cuerpo".

Los elementos de extravagancia del septum, que Enrique conoce, asociado con la percepción abierta de su diversidad sexual, nos hacen definir el uso de este como una provocación, un acto intencional que va a generar la exposición de determinados supuestos, la incitación a la polémica y críticas, tal como le pasó: "Cuando puse la pieza que tengo en la nariz, me comenzaron a decir que, si era puerco y no sé qué, y ya dije que, ¡no! Que a mí me gustó y me lo quise poner porque me gustó” (Enrique, gay, Pedagogía).

Por otra parte, la provocación se constituye justo en los elementos sobre los que se conforman el estigma y la discriminación, por lo que este acto nos parece una forma de resistencia. La provocación ofrece una oportunidad para confrontar al otro, al "normal", al que está legitimado; es una forma de poner "sobre la mesa" los elementos de los arbitrarios culturales, de desafiarlos y de reivindicar su propia individualidad, poniendo en juego la propia zona de abyección. Así, en tanto Enrique es estigmatizado por su opción sexual, la imagen que muestra por medio del septum se entrelaza de forma inevitable con su identidad sexogenérica. Sin embargo, este elemento interseccional y sus efectos son intencionados desde la rebeldía. La provocación, así, es un acto voluntario y lleno de sentido reivindicativo que cuestiona el sentido de lo normal y permitido.

\section{c) Resistencia estratégica}

Otro tipo de resistencias son las que nombramos estratégicas. Estas, aunque hayan comenzado por ser reactivas, no lo son. Se componen por diversas acciones articuladas en tiempo y forma, más que por actos aislados. Como tal, la intencionalidad de esta forma de resistencia echa mano de formas más elaboradas de cálculo y de una economía del acto social. Contiene una lectura más explícita del contexto social que las resistencias reactivas.

Quienes se asumen LGBT han encontrado en su trayectoria escolar pautas de conducta que los han vuelto individuos empoderados, reconocidos en sus espacios escolares por su estatus académico, lo que ha limitado las expresiones de violencia en su contra:

Descubrí que era bueno para redactar y para algunas cosas y eso hacía que ellos se acercaran a hablarme [...] hasta cierto punto me dio como cierto empoderamiento, en el sentido de que ya no me veían nada más de: "Me llevo con Alberto, lo relajeo, pero lo respeto bastante porque él puede ser mi compañero de equipo y me va a ir bien". Entonces, hasta cierto punto me aproveché de esa situación, sí me aproveché bastante. Como me di cuenta de eso no dejé de ser así, seguí invirtiendo en esa parte porque recibía ese reconocimiento académico y el respeto [...] fue una manera de resistir a las agresiones, de imponerme ante eso y a ellos (Alberto, gay, Pedagogía).

En este caso, el participante ha construido un perfomance producto de una compleja lectura académica en el cual se encuentra presente el proceso de acreditación, estatus y competencias académicas. La 
performatividad, en tanto acto reiterativo (Butler, 1990), en este caso tiene toda la intencionalidad de un acto consciente por medio de generar una "moneda de cambio" ante la cual logra empoderarse, y la percepción de su opción sexual diversa es omitida ante este elemento, de tal forma que logra "imponerse" frente a los posibles efectos adversos de la heteronormatividad, pero también logra representar una imagen de poder en su espacio. Así, el estatus académico, en este caso, media la construcción de una esfera de poder ante la cual "saca provecho". Este se intersecta de forma positiva quitándole potencia al estigma de la diversidad sexual. Así, la intersección, además de potenciar las violencias simultáneas, también puede limitarlas.

Ahora bien, hemos insistido en que los actos estratégicos son acciones más complejas en comparación con las resistencias más reactivas, como devolver inmediatamente el golpe o el insulto espontáneo. Están mediados también por una lectura del contexto, pero no intervienen en la movilización consciente de tantos elementos, como sucede en las resistencias reactivas.

Con esta complejidad sugerida, el aprendizaje es producto de un proceso más o menos largo y no tan espontáneo. En el caso de Alberto este aprendizaje surge desde la preparatoria, tal como reporta: "Desde la preparatoria me di cuenta, lo vine utilizando y fue la manera de imponerme ante esas situaciones" (Alberto, gay, Pedagogía). Así, la universidad es un espacio donde se actualizan formas de resistencia, al igual que sucede con las manifestaciones de discriminación. El caso de Alberto no es el único, Oliver también ha construido esta forma de resistencia:

E. ¿Hasta qué punto construiste a esa persona? En futbol participas, en basquetbol, en danza, eres un estudiante destacado en tu salón. ¿ Hasta qué punto eso ha sido consciente para ganar seguridad o que no te molesten, como una especie de protección?

P. Yo creo que sí, en parte lo hice. Me acuerdo en primaria siempre sufríamos como bullying [...] Mi mamá siempre me ponía unos pants que se amarran de acá, y como era muy distraído, me los bajaban y te quedan viendo y te da pena... Siempre pensé: "Si hago esto, no me va a pasar esto". En cierto modo sí lo hice para protegerme (Oliver, gay, Comunicación Intercultural). ${ }^{13}$

Una modalidad de resistencia estratégica consiste en que los y las participantes producen una apropiación y una reivindicación conscientes de los vocativos más vejatorios, cercanas a lo que expresa el término queer. Con ello, se adelantan al uso del término en sentido discriminatorio y lo despojan, mediante un proceso intencional simbólico, de sus efectos denigrantes, por lo menos a nivel personal, pero que en la práctica tiene alcances limitados a los colectivos LGBT.

estoy en un colectivo de San Cristóbal, es un colectivo LGBT [...] Ahí me entró la noción de gritar "soy puto, soy joto". Y no me daña en nada porque creo que seguir pensando que es una grosería y

\footnotetext{
${ }^{13}$ Hombre, gay, 25 años, quinto semestre: "Yo vengo de un lugar que se llama [...], ahí estudié la primaria, secundaria, preparatoria y después de ahí me fui a la ciudad de México, tenía como 16 años, soy como el más joven de la generación de allá. A esa edad aprendí a trabajar, hacer todo bajo mi responsabilidad. En la ciudad de México me puse a trabajar de muchas cosas. Las causas por las que me fui de Chiapas fueron por obvias razones, por mis preferencias, digamos. Soy gay, por eso salí. Ya habían pasado varias cosas antes, hasta me traumó por cierto tiempo [...] pero siempre me decían 'Se le va a dar' [ser gay]. Hablo tseltal, es mi lengua materna. El español lo aprendí cuando fui a la ciudad de México. Incluso cuando llegué allá casi no sabía nada de español”.
} 
no un término para decir homosexual, es como que... siento que te lastimas a ti, cuando puedes utilizar esas palabras... se puede decir normalizar y no hay problema. Con mis amigos jugamos de "Pinche puto", cosas así, y no me siento mal. De hecho, a las personas que conozco les digo que soy puto (Carlos, gay, Medicina). ${ }^{14}$

Llama la atención que la discriminación por el uso de los insultos tampoco es un asunto natural. Carlos concibe que tiene el poder de construir un significado diferente a esos apelativos peyorativos y que en ese proceso "no te lastimas a ti mismo", es decir, tiene la agencia para poder concebir que el maltrato no es únicamente un asunto que venga del exterior, sino que siempre necesita de su participación, en alguna medida y dependiendo de la circunstancia, aludiendo a profundos procesos deconstructivos.

Si la otra persona tiene un término para decirte que eres homosexual, que eres afeminado, puede que maneje ese término [...] Siento que presentarte como persona como joto, la otra persona lo pone en jaque. De hecho, no me siento mal que me digan joto, maricón, mampo, sé que soy una persona homosexual y ellos así usan el término (Carlos, gay, Medicina).

Esta no es una experiencia como la anterior, en la cual la repetición continua y cotidiana hace pasar por normal el uso de tales términos, pero, en su recepción, incluso naturalizada, sigue repercutiendo a nivel moral y psicológico. La experiencia que genera Carlos es otra. Él reconoce que esos términos le ocasionan malestar, y en la socialización que ha construido descubre que pueden tener otro significado, hasta como pugna o reclamo en un movimiento social. Por medio de esta vivencia recrea los términos y los utiliza para presentarse ante los demás. Asumirse abiertamente como gay, incluso desde el ritual de la presentación, percibe que es un acto que saca de lugar a posibles agentes. ${ }^{15}$ Esta reapropiación de los términos "puto", "mampo" y "maricón" hace posible que no se sienta agredido ante su posible uso. Es una estrategia personal y colectiva que se apoya en las mismas herramientas de la heteronormatividad para dejarlas sin eficacia.

Este fenómeno no es aislado. Darwin Petate también hace uso de esta forma de reivindicación.

Usar marica es un modo de recordarnos cómo nos percibe el resto del mundo, es un modo de decirnos a nosotros mismos y nosotras mismas que tenemos que ser ingeniosas y encantadoras para tener una vida hermosa en el mundo hetero... Marica a diferencia de gay no es masculino, es femenino. Viene de mariquita, diminutivo de María. Es un modo de cerrar filas y olvidarnos temporalmente nuestras

\footnotetext{
${ }^{14}$ Hombre, gay, 21 años, sexto semestre. Se considera "una persona con muchas habilidades artísticas, soy una persona comprometida, pero igual me gusta interactuar, me considero una persona social, algunos me ponen el calificativo de extrovertido que debo aceptar, es verdad. Me di cuenta que era diferente, porque no tenía idea que era homosexual, puto o maricón, porque yo veía a ciertos niños en el kínder bonitos. En la primaria sufrí mucho bullying, no sé si por ser un niño afeminado o tal vez aplicado o por ambas. Sí sufría un poco de discriminación, pero no tenía eso de sentirme menos, igual participaba, jugaba futbol, voleibol y todo el pedo. En la primaria ya miraba a los chavos bonitos y los chavos ya empezaban con eso de las groserías 'Oye puto, oye maricón' y yo empecé a tomar conceptos como malos, o sea si te gusta un hombre eres como menos".

${ }^{15}$ Referencia a la trilogía de The Matrix dirigida por los hermanos Wachowsky, ahora hermanas Wachowsky, de manera precisa a la naturaleza de los agentes que podían in-corporarse en el cuerpo de cualquier hombre, mujer, niño o niña al estar conectados a la matrix. Hace referencia a que la matrix no es una persona, a la vez que, en el momento preciso, lo somos todos. Todos nos volvemos agentes frente a la anomalía, en el presente caso, frente a la diversidad sexual.
} 
diferencias individuales porque nos enfrentamos a un permanente enemigo común. La palabra Marica puede ser una palabra que han utilizado para atacarnos ... Yo lo utilizo desde esta posición política de asumirme en femenino para contrarrestar esta violencia que se padece de agresión verbal y simbólica, que siempre se ha utilizado para atacarnos desde los discursos, desde las palabras, puto, joto, choto, culero, maricón, mampo. Yo lo utilizo desde ese contexto para politizarme (Darwin, género fluido-marica, activista). ${ }^{16}$

Como puede apreciarse, estos procesos de reivindicación son parte de una acción política que tiene el objetivo de crear colectivos utilizando una bandera que recuerda su lucha, sus precariedades y sus fines. En este tipo de procesos existe todo un mecanismo de agencia, el cual interviene en el desmontaje de las palabras del aparato heteronormado. En este cambio de sentido, las palabras adquieren otra función y significado, hasta como bandera de lucha y reclamo: ¡soy marica! es enaltecer y portar con orgullo su diversidad.

Otras de las formas de resistencia estratégica tienen que ver con las propuestas elaboradas por quienes participaron en nuestro estudio. Desde el sentido común y sus aprendizajes académicos, conciben que lo que le falta a la población estudiantil en general es información, por lo que sería conveniente abordar el tema mediante carteles, conferencias o pláticas, tal como lo considera Andrés ${ }^{17}$ (gay, Comunicación Intercultural), que también ha pensado en el formato de documental. Al respecto Oliver ${ }^{18}$ piensa que se deben crear escuelas como Summerhill, ${ }^{19}$ libres de prejuicios sobre la "condición social, sexual, raza, cultura, lengua, género, aquí se respeta todo" (gay, Pedagogía). O como considera Víctor: "Se tendría que realizar alguna cuestión performática que tenga que ver con lo artístico-lúdico, más que alguien te venga a decir que la identidad de género, la expresión, bla, bla, bla” (Víctor, no binario, Comunicación Intercultural).

\footnotetext{
${ }^{16}$ Abogado de formación. Actualmente trabaja en una asociación civil por los derechos de las personas LGBT.

${ }^{17}$ Hombre, gay, 22 años. Se describe del siguiente modo: "para todos es difícil declararnos, para unas personas más que otras. Pero siento que cuando eres una persona lesbiana o gay y no das apertura para decírselo a otras personas, estás como muy reprimido y no eres la persona que realmente eres. Y cuando ya muchas personas lo saben o te animas a decírselo a tus papás como que tiene consecuencias, sus negativos y positivos. Realmente me costó mucho salir del clóset. Con mi papá, en algunas ocasiones sufría discriminación, no tan profunda, sino verbal, porque mi papá no estaba de acuerdo con eso. Pero cuando decidí decirle a mis hermanos y a mis papás poco a poco se fue dando eso de los papás de que eres mi hijo y te voy a querer como sea, pero claro tiene su dificultad y poco a poco nos van aceptando. Fue un proceso muy difícil”.

${ }^{18}$ Hombre, gay, 21 años, estudiante de quinto semestre. Se considera: "una persona humanista, le pongo atención a las personas que tienen problemas, si puedo les doy consejos. También me considero una persona amistosa, que comparto valores y moral con ellos. Yo no puedo decir de las personas que me caen mal o me caen, primero tengo que conocer a la persona. Me gusta hacer amistades. Personas que veo, les hablo, les pregunto su nombre, su salón, para tener una amistad. Siento que soy muy sensible".

${ }^{19}$ Nombre de la escuela que fundó Alexander Sutherland Neil, regida por el principio de autoregulación del alumnado. Las clases eran voluntarias, las asambleas eran dirigidas por el mismo estudiantado, que planteaba sus problemas y creaba las reglas o leyes para su solución. La opinión de las personas adultas no tenía más valor que la de cualquier estudiante. Su propuesta pedagógica es parte de la corriente antiautoritaria.

${ }^{20}$ Hombre, no binario, séptimo semestre. Considera que es "una persona que me interesa mucho el aprender, creo que desde muy niño ha sido lo que más me mueve, también soy una persona bastante sensible y una persona que está muy enfocado en sus objetivos, tiendo a no ser tan sociable porque estoy concentrado en lo que quiero hacer, en este sentido, mi carrera universitaria. Me interesan mucho las artes, así que por esa parte estoy experimentando. Creo que uno de los valores que para mí es importante es el hecho de ser consciente de que soy un ser humano y que forma parte de un complejo sistema. En ese sentido yo no tengo una religión, pero me considero una persona bastante espiritual, sobre todo en lo relacionado con la naturaleza. Antes tenía muchos problemas de ansiedad social. No podía ni hablar en público, el hecho que la gente me viera, o moverme, era demasiada exposición para mí. Así que el proceso del arte fue un poco terapéutico, para empezar a reconocerme, aceptarme y empezar a ver mi corporalidad".
} 


\section{Conclusión}

La universidad, como otros espacios escolares, se reproduce por medio de perfomance rituales. Tal vez uno de los más característicos tiene que ver con aquellos denominados "bocacalle" (McLaren, 1998), en los que se exacerba, entre otras cosas, el machismo y las expresiones LGBT-D como parte de ese impase libre de movimiento y casi ausente de reglas explícitas y formalidades. Hasta en los rituales más académicos, como la evaluación, la LGBT-D se sigue manifestando en las figuras de los y las docentes. Así, en sus actos diarios la universidad se presenta como una institución normalizadora. Pero, como podemos observar, la universidad no impone un dictado de forma total, sino que las personas disminuidas socialmente se reivindican por medio de actos de resistencia. Estos actos, como oposiciones en el sentido girouxiano, en contra del dictado heteropatriarcal, convierten a la universidad en un campo de conflicto en donde diferentes discursos, prácticas e intereses se enfrentan.

Los resultados de esta investigación permiten mostrar que esta resistencia es más pública de lo que Scott (2000) reconoce en su ámbito de estudio, dado que, aunque no dudamos de que existan discursos ocultos, la confrontación, la provocación y la resistencia estratégica son modalidades del resistir en el escenario público.

También observamos que el género se vuelve una dimensión de la construcción social lleno de rebeldía y contestación y no se encuentra dispuesto y acabado desde la reproducción social. La universidad también funciona, en este sentido, como un escenario de reivindicación de las opciones sexogenéricas no hegemónicas. La universidad es un espacio donde la identidad, entendida desde una ontología del gerundio - ser siendo-, se disputa en contra de los mandatos heteronormativos.

De esta forma, las y los estudiantes LGBT no son víctimas pasivas, sino que elaboran un conjunto de aprendizajes que ponen en práctica para prevenir y contrarrestar las formas de violencia que experimentan. Todas las modalidades de resistencia presentadas, algunas con desarrollos más complejos que otras, muestran que son generadas desde la experiencia vital de cada participante, pero también han demostrado que pueden asociarse con las formaciones académicas, que aportan elementos contrahegemónicos con mayores alcances.

Ahora bien, debemos apuntar una nota final: todo acto necesita una infraestructura - en términos materiales y simbólicos- que permita (que no impida o que apoye) llevarse a cabo, es decir, que le sirva de plataforma. Esto que suele considerarse como obviedad, nos lo recuerda Butler (2014), es de suma importancia porque ninguna lucha o reivindicación puede llevarse a cabo sin una plataforma. Por ejemplo, cuando determinados grupos están en condición de vigilancia y no pueden salir a las calles porque son violentados o presos, la misma calle se convierte en el objetivo de la lucha. La lucha primigenia se lleva a cabo por la misma plataforma de la resistencia. No es diferente a los actos de resistencia en la universidad.

Aunque el espacio universitario, con todo lo que ello implica, está preparado para las expresiones fácticas de la LGBT-D, también lo está para la producción de actos de resistencia y se convierte en una plataforma de reivindicación. Ello nos hace pensar que la universidad sigue siendo un espacio abierto a deconstrucciones. Con ello, se puede recrear como un contexto de esperanza, tal como define Holloway (2010) los intersticios del poder donde crecen las autonomías y rebeldías frente a los sistemas de opresión.

En la universidad, en sus salones, cafeterías y otras áreas, se presencian actos de confrontación y provocación por parte de estudiantes LGBT que la infraestructura material y simbólica no impide que 
se generen. Claro está, estos espacios de resistencias son construidos performáticamente en el mismo momento de la acción de resistencia. Lo que deseamos enfatizar es que si los actos de resistencia pueden generarse en la universidad es porque hay grietas en el sistema de discriminación que dan lugar a la acción reivindicatoria de las y los estudiantes LGBT, aún a costa de la voluntad y del consenso heteropatriarcal y de sus políticas culturales en la universidad.

Pero, siendo así, al mismo tiempo nos percatamos del valor de los actos de resistencia en general, y en particular de los protagonizados por las y los estudiantes LGBT; con la acción de la resistencia, a la par, se crean espacios de oposición al dictado social, es decir, plataformas para la democratización de los espacios. Así, la resistencia abre condiciones, como la infraestructural, que van a contrapelo de las desigualdades. Las resistencias de las y los estudiantes LGBT, por sí mismas, hacen de la universidad un lugar más democrático, más vivible. Su lucha, sus resistencias diarias, confrontaciones, provocaciones, estrategias y discursos precisamente abren mundo, y lo abren como igualdad y dignidad.

\section{Referencias}

Amigot, P., y Pujal i Llombart, M. (2009). Una lectura del género como dispositivo de poder. Sociológica, (70), 115-152. http://www.sociologicamexico.azc.uam.mx/index.php/Sociologica/article/view/145

Baruch Domínguez, R., Pérez Baeza, R., Valencia Toledano, J., y Rojas Cortés, A. (2017). 2da Encuesta Nacional Sobre Violencia Escolar Basada en la Orientación Sexual, Identidad y Expresión de Género hacia estudiantes LGBT en México. Fundación Arcoíris por el Respeto a la Diversidad Sexual A.C.; Clóset de Sor Juana A.C.; Inspira Cambio A.C.; Coalición de Jóvenes por la Educación y la Salud Sexual COJESS México; Espolea A.C. http:// www.fundacionarcoiris.org.mx/wp-content/uploads/2017/08/Reporte-Encuesta-Bullying-2017-final.pdf

Bourdieu, P. (1998). La dominación masculina. Anagrama.

Butler, J. (1990). Actos performativos y constitución del género: ensayo sobre fenomenología y teoría feminista. En C. Sue-Ellen, Performing Feminisms: Feminist Critical Theory and Theatre (pp. 296-314). Johns Hopkins University Press.

Butler, J. (2006). Vida precaria. Paidós.

Butler, J. (2007). El género en disputa. Paidós.

Butler,J. (2014). Repensar la vulnerabilidady la resistencia [conferencia]. XV Simposio Internacional de la Asociación Internacional de Filósofas: Filosofía, Conocimiento y Prácticas Feministas. https://docs.google.com/file/ d/OB7q9qMj2JyYRWGtyR-zk2QlhESIU/edit?pli=1

Comisión Interamericana de Derechos Humanos (CIDH). (2015). Violencia contra las personas lesbianas, gay, bisexuales, trans e intersex en América. CIDH.

De Oliveira, J. M. (2019). Tránsitos de género: lecturas queers/trans de la potencia del rizoma de género. Revista de Educación, X(18), 31-48. https://fh.mdp.edu.ar/revistas/index.php/r_educ/article/view/3748

Diagnóstico sobre atención a personas lesbianas, gays, bisexuales y trans en el estado de Chiapas (2017). Instituto Nacional de Desarrollo Social; Fundación Arcoíris.

Foucault, M. (1980). Microfísica del poder. Edisa.

Foucault, M. (1998). Historia de la sexualidad I. La voluntad de saber. Siglo XXI.

Foucault, M. (2002). Vigilary castigar. Siglo XXI.

Foucault, M. (2007). Nacimiento de la biopolitica. Fondo de Cultura Económica.

Giroux, H. (1985). Teorías de la reproducción y la resistencia en la nueva sociología de la educación: un análisis crítico. Cuadernos Políticos, (44), 36-65. http://www.cuadernospoliticos.unam.mx/cuadernos/contenido/ CP.44/cp.44.6.\%20HenryAGiroux.pdf

Giroux, H. (1992). Teoría y resistencia en educación. Siglo XXI.

Heidegger, M. (2009). Ser y tiempo. Trotta.

Holloway, J. (2010). Crack Capitalism. Benemérita Universidad Autónoma de Puebla; PlutosPress.

McLaren, P. (1998). Los símbolos en el aula y las dimensiones rituales de la escolaridad. En H. Giroux y P. McLaren, Sociedad, cultura y educación (pp. 41-78). Miño y Dávila. 
Movimiento de Integración y Liberación Homosexual (Movilh). (2010). Educando en la diversidad. Orientación sexual e identidad de género en las aulas. Movilh. http://www.movilh.cl/documentacion/educando_en_la diversidad_2da_edicion_web.pdf

Otero, L. (2017). Actitudes frente a la diversidad sexual entre los estudiantes de Trabajo Social mexicanos: el contexto regiomontano. Cuadernos de Trabajo Social, 30(2), 417-433. https://doi.org/10.5209/CUTS.52131

Otero, L., y Martínez, L. (2016). Sexismo y actitudes hacia la homosexualidad, la bisexualidad y transexualidad en estudiantes de Trabajo Social mexicano. Trabajo Social Global. Revista de Investigaciones en Intervención Social, 6(11), 3-30. https://doi.org/10.30827/tsg-gsw.v6ill.5181

Piña, J. m., y Aguayo, H. (2015). Homofobia en estudiantes universitarios de México. Región y Sociedad, 27(64), 5-35. https://doi.org/10.22198/rys.2015.64.a309

Platero, R. (2012). Intersecciones: cuerpos y sexualidades en la encrucijada. Bellaterra.

Portugal, R. (201l, 1 de noviembre). Estudios sobre homoparentalidad: revisión científica y análisis metodológico. Federación Estatal de Lesbianas, Gais, Trans y Bisexuales. http://www.felgtb.org/temas/familias/ documentacion/investigaciones/i/1382/531/estudios-sobre-homoparentalidad-revision-cientifica-yanalisis-metodologico

Proceso (2017, 12 de mayo). El 49.75\% de estudiantes de la comunidad LGBTI son víctimas de acoso o "bullying", revela encuesta. https:/www.proceso.com.mx/486335/49-75-estudiantes-la-comunidad-lgbti-victimasacoso-bullying-revela-encuesta

Ruiz, A., Evangelista, A., y Xolocotzi, Á. (2018). ¿Cómo llamarle a lo que tiene muchos nombres? ¿Bullying, violencia de género, homofobia o discriminación contra personas LGBTI? Revista Interdisciplinaria de Estudios de Género, 4(4), 1-31. https://doi.org/10.24201/eg.v4i0.210

Secretaría de Economía. (202la, 24 de octubre). San Cristóbal de Las Casas. Data México. https://datamexico.org/ es/profile/geo/san-cristobal-de-las-casas?redirect=true

Secretaría de Economía. (2021b, 24 de octubre). Tapachula. Data México. https://datamexico.org/es/profile/geo/ tapachula?redirect=true

Scott, J. (2000). Los dominados y el arte de la resistencia. Discursos ocultos. Era.

Strauss, A., y Corbin, J. (2002). Bases de la investigación cualitativa. Técnicas y procedimientos para desarrollar la teoría fundamentada. Universidad de Antioquia.

UNESCO (2013). Respuestas del sector de educación frente al bullying homofóbico. Oficina Regional de Educación para América Latina y el Caribe (OREALC/UNESCO Santiago). http://www.unesco.org/new/fileadmin/ MULTIMEDIA/FIELD/Havana/pdf/Educacion_bullying.pdf

UNESCO (2015a). El bullying homofóbico y transfóbico én los centros educativos. Taller de sensibilización para su prevención. Guía de facilitación. Comisión Nacional de los Derechos Humanos. https://www.cndh.org.mx/sites/default/ files/documentos/2019-04/08-Bullying-homofobico.pdf

UNESCO (2015b). La violencia homofóbica y transfóbica en el ámbito escolar: hacia centros de estudios inclusivos y seguros en América Latina. Oficina Regional de Educación para América Latina y el Caribe (OREALC/UNESCO Santiago). https://bibliotecadigital.mineduc.cl/handle/20.500.12365/14966 